\title{
Localization of the GerD spore germination protein in the Bacillus subtilis spore
}

\author{
Wiyada Mongkolthanaruk, $†$ Carl Robinson $\ddagger$ and Anne Moir
}

Correspondence

Anne Moir

a.moir@sheffield.ac.uk

Received 1 September 2008

Revised 4 December 2008

Accepted 14 December 2008

\author{
Department of Molecular Biology and Biotechnology, University of Sheffield, Firth Court, Western \\ Bank, Sheffield S10 2TN, UK
}

\begin{abstract}
The GerD protein of Bacillus subtilis is required for efficient spore germination in L-alanine, and for germination in the alternative germinant combination of amino acids plus sugars. Only germination via nutrient receptors is affected in the mutant. The GerD protein is predicted to be a lipoprotein that is produced in the forespore compartment of the sporulating cell. Using antibody raised against the GerD protein, Western blots of proteins from spore fractions revealed that, as might be expected, the protein was detected in the inner membrane of spores, but it was also present at a high level in spore integuments (comprising coat, cortex and germ cell wall layers), and to some extent in the soluble fraction. It is likely that the GerD protein in the outer layers of dormant spores is located in the germ cell wall, as it was detected in coat-defective spores, and in the cell wall fraction of cells that were outgrowing from spores. Which of the multiple locations of GerD is important for its function is not known, but the inner membrane association would be appropriate for any interaction with germinant receptor proteins or SleB cortex lytic enzyme. Substitution of alanine for cysteine in the conserved cleavage site of the predicted prelipoprotein signal sequence of GerD resulted in mutant spores that lacked the GerD protein entirely.
\end{abstract}

\section{INTRODUCTION}

During germination of bacterial endospores, the dormant spore undergoes a number of biophysical and structural changes that lead to the rehydration of the cellular core, which is then able to resume metabolism and commence the macromolecular synthesis associated with spore outgrowth. Efficient germination of Bacillus endospores in response to specific nutrient molecules involves a number of proteins that are already present in the dormant spore (Moir, 2006; Setlow, 2003). Germinant must penetrate the outer layers of the spore to interact with germinant-specific receptors, which are located in the spore inner membrane (Hudson et al., 2001; Paidhungat \& Setlow, 2001). Most endospore formers encode multiple germinant receptors of differing specificity. The best studied to date is the alanine-responsive receptor encoded by the three genes of the paradigm gerA operon (Paidhungat \& Setlow, 2000; Zuberi et al., 1987). Although the physical changes accompanying germination have been extensively described, the mechanism by which the signal is transduced from receptor to other spore components is not well understood. Monovalent cations

tPresent address: Department of Microbiology, Faculty of Science, Khon-Kaen University, Khon-Kaen 40002, Thailand.

łPresent address: Animal Health Trust, Lanwades Park, Kentford, Newmarket, Suffolk CB8 7UU, UK.

Abbreviations: AGFK, asparagine, glucose, fructose and $\mathrm{KCl}$; CaDPA, calcium dipicolinate; DPA, dipicolinic acid.
(Swerdlow et al., 1981), then the spore core component calcium dipicolinate (CaDPA) and other molecules (Setlow et al., 2008) are released from the spore core. The SpoVA proteins are probably important in this CaDPA release (Vepachedu \& Setlow, 2007). At this point the spore is no longer fully heat resistant, but without cortex lysis, the core can not rehydrate sufficiently to allow mobility of core proteins (Cowan et al., 2003) and complete the loss of heat resistance. The spore cortex lytic enzymes SleB (forespore expressed, and localized to both the inner membrane and the coat) and CwlJ (localized to the coat only) are activated, leading to spore cortex degradation and full core rehydration (Chirakkal et al., 2002). CaDPA released from the core is likely to be the activator of the CwlJ cortex lytic enzyme, and CwlJ-dependent spore germination can be induced by high external concentrations of CaDPA, without the involvement of nutrient receptors (Paidhungat et al., 2001).

Another component in the germination apparatus of Bacillus is the GerD protein. Mutations in the gerD gene of Bacillus subtilis result in spores defective in their response to both types of germinant: L-alanine and an amino acid and sugar combination, such as asparagine plus glucose and fructose and $\mathrm{KCl}$ (AGFK). Whatever the role of GerD protein in nutrient germination in Bacillus, it is notable that clostridia do not encode GerD protein homologues, so the function is either not required in clostridia, or is met by an alternative, undefined protein. Some of the earliest described gerD point mutants of $B$. subtilis showed considerable germination in L-alanine, 
though not in AGFK (Warburg et al., 1985). Germination in a gerD-null mutant (Yon et al., 1989), measured as the decrease in OD of a spore suspension, suggested a residual, extremely slow germination in L-alanine by a small proportion of spores, but essentially none in AGFK. Therefore, one possible role for the GerD protein is an as yet undefined role in the receptor-mediated downstream activation of germination events. The GerD protein would be hydrophilic, but it has a potential lipoprotein signal sequence, as does the receptor GerAC component. The gerD gene is expressed in the forespore under the control of the forespore-specific sigma factor $\sigma^{\mathrm{G}}$ (Kemp et al., 1991), and is likely to be directed by the secretion apparatus to the membrane of the forespore, which is the future spore inner membrane, where germinant receptors of the GerA family, SpoVA proteins and germination-specific cortex lytic enzyme SleB are also located.

Non-nutrient germinants, such as CaDPA and dodecylamine, that induce germination without involvement of the germinant receptors, remain effective germinants in a gerD mutant (Pelczar et al., 2007); the data obtained in the present study confirm this observation, and demonstrate that the response of gerD mutants is not improved by spore coat depletion. Using antibodies raised against the GerD protein itself, GerD has been detected efficiently in wildtype spores, without the need to overexpress the protein. Western blotting evidence suggests that the GerD protein is present in the inner membrane of spores and, presumably following release from the inner membrane, also in the integuments (the insoluble layers of the spore) and the soluble fraction. Various lines of evidence, including the persistence of the protein in germinated spores and in the cell walls of outgrowing cells after germination, suggest that integument-associated GerD protein is probably associated with the germ cell wall peptidoglycan, which is not degraded during germination.

\section{METHODS}

Strains and media Strains are listed in Table 1. B subtilis strains were routinely cultured in Oxoid nutrient broth (NB), or on Oxoid nutrient agar, and Escherichia coli was cultured on L agar; media contained antibiotics where appropriate. Spores were produced in casein hydrolysate yeast-containing (CCY) medium, and harvested and washed, as previously described (Hudson et al., 2001). Spores were heat activated in water at $70{ }^{\circ} \mathrm{C}$ for $30 \mathrm{~min}$, stored on ice, and used within $6 \mathrm{~h}$. Germination at $37^{\circ} \mathrm{C}$ in response to nutrient germinants was in $10 \mathrm{mM}$ Tris/ $\mathrm{HCl}, \mathrm{pH} 7.6$, containing L-alanine $(1 \mathrm{mM})$ and $\mathrm{KCl}(20 \mathrm{mM})$, or in AGFK (L-asparagine, D-glucose, Dfructose and $\mathrm{KCl}$, at $30,5.6,5.6$ and $20 \mathrm{mM}$, respectively) in $50 \mathrm{mM}$ Tris/HCl, pH 8.4. Release of dipicolinic acid (DPA) in germination experiments was measured according to the method of Scott \& Ellar, (1978).

Construction of $\boldsymbol{c o t E}$ derivatives. Spores lacking CotE have a lysozyme-permeable and incomplete spore coat (Little \& Driks, 2001). A cotE: : cat mutation from strain ER221 (cotH:: spect, $\operatorname{cotE}::$ cat) was introduced into competent cells of PS832 and AM1621 by transformation. Chloramphenicol-resistant, spectinomycin-sensitive transformants in PS832 and AM1621 were named AM1635 and AM1636, respectively. The transformants were retained, and the lysozyme permeability of spores was confirmed. Germination experiments were generally carried out in a PS832 genetic background, for comparison with work from other laboratories.

\begin{abstract}
Alteration of the predicted prelipoprotein cleavage sequence of GerD. A C20A amino acid substitution was introduced into the GerD protein, and this removed the site of potential lipomodification. The $7.4 \mathrm{~kb}$ plasmid pBMD16 (Yon, 1986), containing the complete gerD gene on a $1.8 \mathrm{~kb}$ Pst $\mathrm{I}$ fragment, was used as a template for mutagenesis, using the Stratagene QuikChange II XL site-directed mutagenesis kit, with primers MutD1 (GTTATTATCTGTAACAGCTGCCGCTCCAAAAGACCAAGC) and MutD2 (GCTTGGTCTTTTGGAGCGGCAGCTGTTACAGATAATAAC) (the altered bases are underlined). The mutation was checked by sequencing, and the gerD mutant allele was introduced to the B. subtilis chromosome by congression. Plasmid DNA $(8 \mu \mathrm{g})$ was linearized with ScaI, and introduced into a $100 \mu \mathrm{l}$ suspension of competent cells of B. subtilis 1604 , which is our laboratory wild-type, by congression with $15 \mathrm{ng}$ $\operatorname{trp}^{+}$DNA from B. subtilis 666. Of $61 \mathrm{Trp}^{+}$transformants screened, two were $\mathrm{Ger}^{-}$, as scored by the tetrazolium germination colony screen (Moir et al., 1979). The gerD mutation that had been introduced was confirmed in chromosomal DNA of transformant strain 1656 by DNA sequencing of the PCR-amplified gerD gene.
\end{abstract}

Spore permeabilization. The method used was that described by Brown et al. (1982). Spores were incubated at $37{ }^{\circ} \mathrm{C}$ for $90 \mathrm{~min}$ in $5 \mathrm{mM}$ CHES buffer, $\mathrm{pH} 8.6$, containing $8 \mathrm{M}$ urea, $70 \mathrm{mM}$ DTT and $1 \%(\mathrm{w} / \mathrm{v})$ SDS, and then they were washed five times in distilled water

Table 1. Strains used in this study

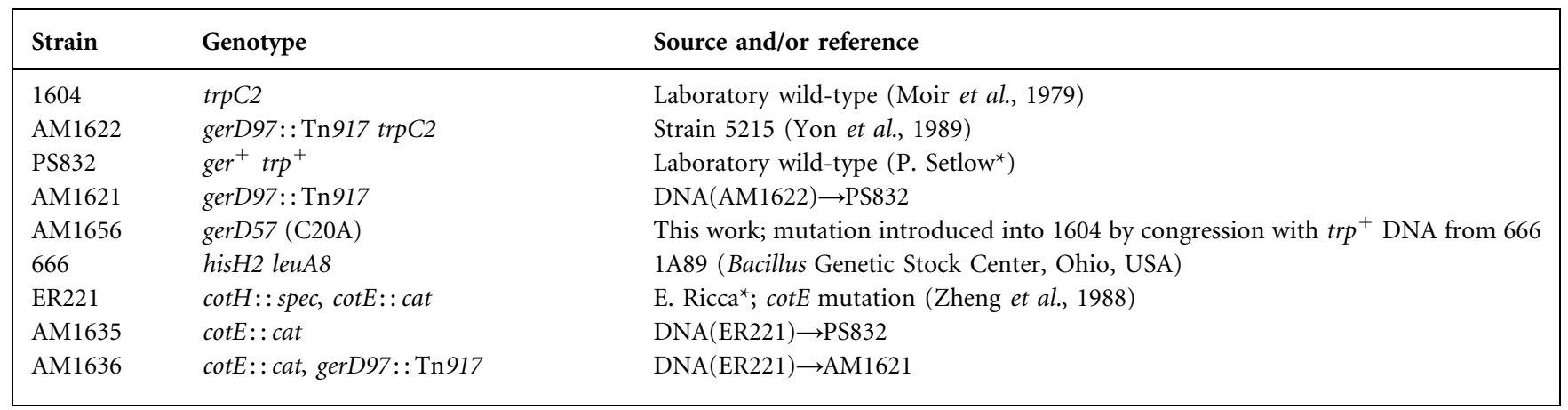

${ }^{\star}$ P. Setlow, University of Connecticut Health Center, Farmington, USA; E. Ricca, Federico II University, Naples, Italy. 
by repeated centrifugation. Spores were confirmed as phase bright and lysozyme sensitive.

Production of an anti-GerD antibody. A $0.34 \mathrm{~kb}$ fragment of the gerD gene (encoding aa residues 32-139) was cloned into the expression vector pGEX-3X (Pharmacia), in-frame with the glutathione $S$-transferase ORF, yielding plasmid pCR20, which encodes a glutathione-S-transferase-GerD fusion protein of $40.5 \mathrm{kDa}$, with a cleavage site for the protease factor Xa between the two domains. Transformants carrying pCR20 were induced with IPTG $(0.1 \mathrm{mM})$ for $4 \mathrm{~h}$ at $37^{\circ} \mathrm{C}$, and the soluble fusion protein was affinity purified by binding to glutathione-agarose beads. Following cleavage from the resin by Factor Xa, the GerD domain was recovered, and used to generate a polyclonal antibody in rabbits, as previously described (Hudson et al., 2001), but using $30 \mu \mathrm{g}$ protein for both initial and booster injections (Robinson, 1996). The antiserum was stored at $-20{ }^{\circ} \mathrm{C}$, and was passed through a column containing immobilized $E$. coli lysate (Pierce) before use in Western blotting.

Spore fractionation procedures. Spores of B. subtilis strain 1604 (wild-type) and strain 5215 (gerD97:: Tn917) were broken by shaking with glass beads in a Bio 101 Fastprep, as described (Hudson et al., 2001). The genetic background was that used in our past fractionation work, to ensure comparability. After removal of the glass beads, whole crude extracts were centrifuged at low speed to sediment the insoluble integument fraction, which was predicted to consist of the broken spore coats, cortex and primordial germ cell wall. The supernatant fraction from these crude extracts contains inner membrane and the soluble proteins. In some experiments this supernatant was further fractionated by ultracentrifugation to separate inner membrane from soluble proteins, and these fractions were checked by electron microscopy.

The protein content in extracts was estimated by the Peterson assay (Peterson, 1977). Aliquots, adjusted so that fractions loaded would represent material from equivalent numbers of spores, were boiled in SDS-PAGE sample buffer, briefly centrifuged to remove any remaining insoluble material, and then separated by SDS-PAGE on precast gels [10-20\% (w/v) Tris-glycine or NuPage $4-12 \%(w / v)$ BisTris; Invitrogen]. The proteins were transferred onto a nitrocellulose membrane, probed with anti-GerD primary antibody $(1: 100$ dilution), and detected with horseradish-peroxidase-linked antirabbit IgG secondary antibody (1:2000 dilution), using an ECLPlus Western blotting detection kit (GE Healthcare).

\section{RESULTS}

\section{Effects of spore coat depletion}

Spores of a gerD mutant germinate normally in the nonnutrient germinants CaDPA and dodecylamine, and GerD function is required only for nutrient-receptor-mediated germination (Pelczar et al., 2007). A decreased spore coat permeability to germinant can cause a defect in germination in alanine and in amino acid plus sugar combinations: for example, the gerP mutants of Bacillus cereus and $B$. subtilis are defective in response to nutrient germinants, but recover their responsiveness to germinants if the spore coats are removed. For the gerD mutant, spore coat permeabilization was achieved by two alternative approaches: chemical decoating, and spore coat depletion by inclusion of a $\cot E$ mutation (Fig. 1). The germination response of the gerD mutant, as measured by loss of heat resistance, was very limited, and there was no significant release of DPA; this did not improve on chemical depletion of spore coat (Fig. 1a). This failure to release any DPA was also observed in alanine-stimulated germination (data not shown). In addition, introduction of a $\cot E$ mutation to the wild-type and to a gerD mutant did not significantly improve germination rates (Fig. 1b). In contrast, germination in dodecylamine was more rapid in coat-defective $\cot E$ mutant spores (data not shown); this presumably reflects improved access of dodecylamine to the inner spore membrane, which is its target in the spore.

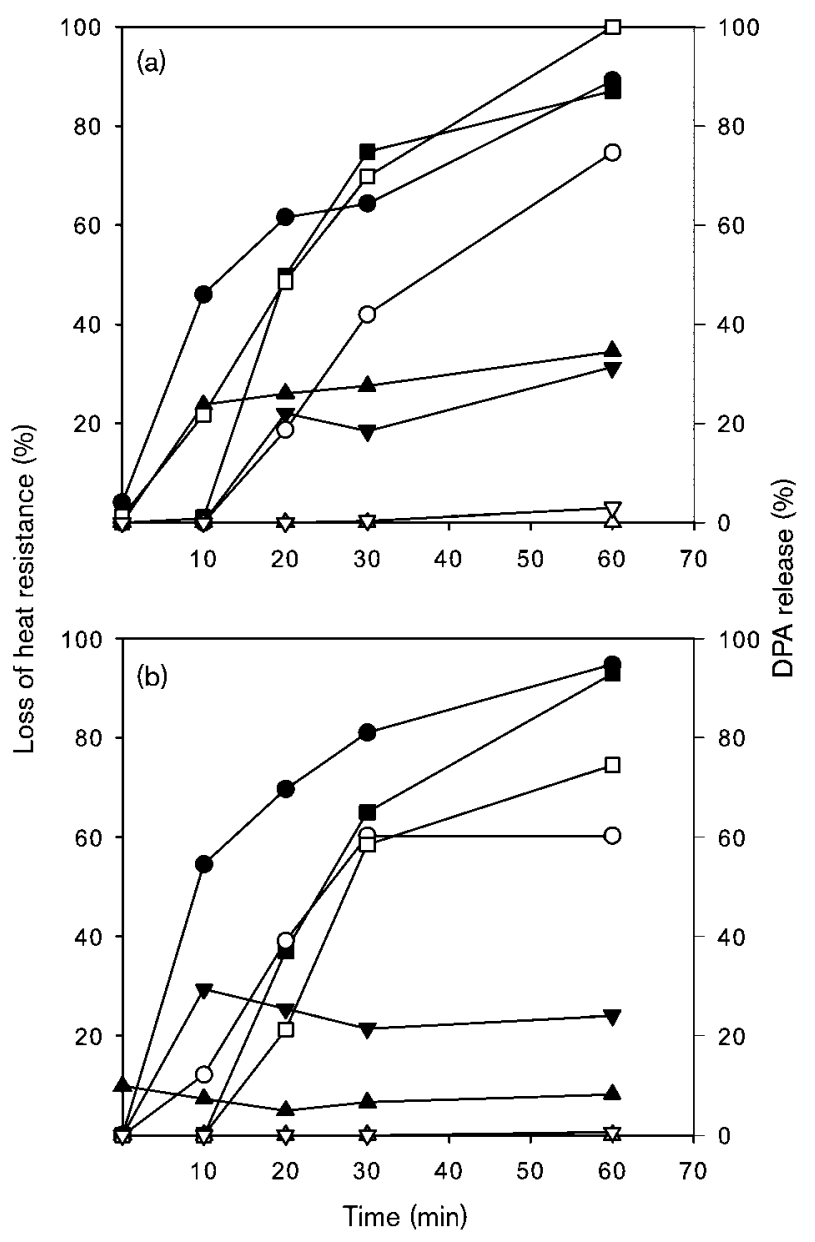

Fig. 1. The spore coat does not represent a barrier to germination of ger $D$ mutant spores. Spores were heat activated and germinated at $37{ }^{\circ} \mathrm{C}$ in AGFK, and germination was followed by measurement of the proportion of heat-resistant organisms (filled symbols), and the release of DPA into the supernatant (open symbols). No significant DPA release was seen in germination of the gerD or ger $D$ cotE mutant strains; these data points are superimposed on the baseline. (a) Germination following chemical decoating. $\bigcirc$, PS832; $\square$, decoated PS832; $\Delta \triangle$, AM1621(gerD); $\nabla$, decoated AM1621(gerD). (b) Effect of a $\cot E$ mutation on germination behaviour. $\bigcirc, \mathrm{PS} 832 ; \Delta \triangle, \mathrm{AM} 1621(\mathrm{ger} D)$; $\square$, AM1635 (cotE); $\nabla \nabla, A M 1636$ (gerD cotE). 


\section{GerD is present in multiple locations in the spore}

Western blots were performed on spore extracts to explore the localization of GerD protein in the spore (Fig. 2). The anti-GerD antibody detected a $19 \mathrm{kDa}$ band in the total spore extract from glass-bead disrupted wild-type spores (Fig. 2a, lane 2) that was absent from extracts of the gerDnull mutant 5215 (gerD::Tn917; Fig. 2a, lane 3). This confirmed that the $19 \mathrm{kDa}$ band observed was GerD protein. In lane 2 , an additional band, which was not seen in the gerD mutant spore extract at $\sim 10 \mathrm{kDa}$, could be a degradation product of GerD, and it was present in variable amounts in experiments using different wild-type spore preparations. Spores were broken by bead-beating, and fractionated into integument, inner membrane and soluble fractions using a procedure identical to that described by Hudson et al. (2001). The integument fraction was demonstrated to contain spore outer membrane, as well as coat and cortex (Hudson et al., 2001). The GerD protein was detected at significant levels in all three fractions (Fig. 2a, lanes 4, 5 and 6), with at least $50 \%$ in the integument fraction. Examination of the SDS-PAGEseparated total protein profiles of these fractions, and visualization of the material by electron microscopy, confirmed that the fractions were not significantly crosscontaminated (Mongkolthanaruk, 2007); therefore the GerD protein appeared to be located in more than one place in the spore. As the integument fraction contains multiple components, including both cortex and spore coat, the probable location of the GerD protein within this fraction was explored. GerD protein was found in both integument and supernatant (soluble plus inner membrane) fractions of AM1635 ( $\cot E)$, which is a severely coatdefective mutant (Fig. 2b, lanes 2 and 3); therefore, GerD is unlikely to be located in the coat. In extracts of the $\cot E$ mutant (lanes 2 and 3), an additional band of GerD-related material was seen at $38 \mathrm{kDa}$. This band was also visible in the membrane fraction of wild-type spores (Fig. 2a, lane 6), and may represent a complex, or possibly a dimer, of GerD.

\section{Detection of GerD protein in germinated and outgrowing spores}

The purpose of this experiment was to define more specifically the location of GerD in the integument fraction, by testing whether GerD remained associated with spores and outgrowing cells after germination. In order to include a gerD mutant control, we germinated spores in CaDPA, in which both wild-type and mutant would germinate efficiently, then outgrew in rich broth. Therefore this was not a test of the fate of GerD in circumstances where it could be directly involved in germination. Spores of strains 1604 and 5215 (at $\mathrm{OD}_{600}$ of 0.5 ) were germinated in $20 \mathrm{ml}$ CaDPA solution at room temperature $\left(20^{\circ} \mathrm{C}\right)$ for $1 \mathrm{~h}$, and the samples were centrifuged to collect the germinated spores, which were confirmed as phase dark by microscopy. Half of the germinated spores were incubated for outgrowth in $20 \mathrm{ml}$ $\mathrm{NB}$ at $37{ }^{\circ} \mathrm{C}$ for $1 \mathrm{~h}$. The samples were then examined by (a)

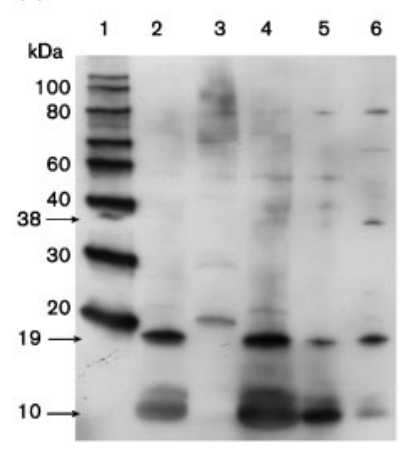

(b)

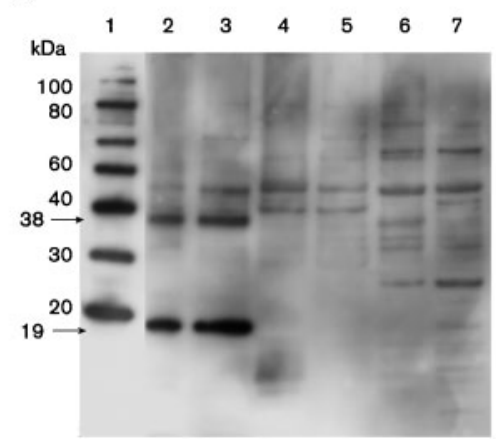

(c)

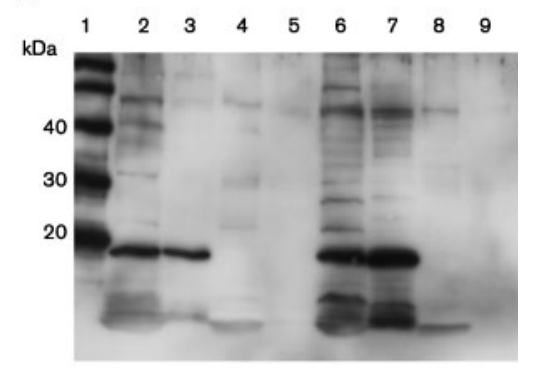

Fig. 2. Detection of GerD protein in spore fractions by Western blotting. Proteins were separated by SDS-PAGE on a 10$20 \%$ Tris-glycine gel, and blotted onto a PVDF membrane. Bound antibody was detected by enhanced chemiluminesence. Loading of spore fractions was adjusted so that each represents material from an equivalent number of spores. (a) Detection of GerD in spore fractions. Lanes: 1, magic marker (20-120 kDa; Invitrogen); 2, crude spore extract of 1604 (wild-type); 3, equivalent crude spore extract of AM1622 (gerD); 4-6, integument, membrane and soluble fractions of 1604, respectively. (b) Testing for the presence of GerD in mutant spores. Spore extracts (integument and supernatant) were separated by SDSPAGE on NuPage 4-12\% (w/v) Bis-Tris gel. Lanes: 1, magic marker; 2 and 3, integument and supernatant fractions, respectively, of $A M 1635$ ( $\cot E) ; 4$ and 5, integument and supernatant fractions, respectively, of $A M 1656$ ( $C 20 A$ substitution in GerD); 6 and 7, pellet and supernatant fractions, respectively, of vegetative cells of 1604. (c) GerD protein in germinated spores and outgrowing cells. Spores were germinated in CaDPA, and transferred to NB for outgrowth. Lanes 1 , magic marker; 2 and 3 , integument and supernatant of germinated spores, respectively, of $1604\left(\mathrm{ger}^{+}\right) ; 4$ and 5 , integument and supernatant of germinated spores, respectively, of AM1622 (gerD:: Tn917); 6 and 7, pellet and supernatant of outgrowing cells, respectively, of strain $1604\left(\mathrm{ger}^{+}\right) ; 8$ and 9, pellet and supernatant of outgrowing cells, respectively, of AM1622 (gerD::Tn917). 
light microscopy, and they were found to contain short rods. For comparison, vegetative cells were grown to midexponential phase in NB from fresh spore-free inocula. The germinated spores, outgrowing cells and vegetative cells were broken with glass beads by the Fastprep method, and integument per cell wall, and supernatant fractions, were tested for GerD by Western blotting.

The results showed that GerD was present in both integument and supernatant fractions of germinated spores (Fig. 2c, lanes 2 and 3) and outgrowing cells (Fig. 2c, lanes 6 and 7) of the wild-type, but, as expected, it was absent from vegetative cells (Fig. 2b, lanes 6 and 7). GerD is unlikely to be associated with spore cortex, as it is present in outgrowing cells, and in integument and supernatant fractions, long after cortex hydrolysis. The integument fraction in outgrowing cells contains cell wall material, including spore-derived germ cell wall, and it is therefore a more probable location for GerD protein in the spore.

\section{The consequences of a C20A alteration in GerD}

The GerD protein contains a predicted prelipoprotein signal sequence, followed by a recognition sequence for diacylglycerol addition (Yon et al., 1989), as is also the case for GerAC, GerBC and GerKC receptor proteins. During secretion of forespore-expressed lipoproteins across the inner forespore membrane, the GerF (Lgt) prelipoprotein diacylglyceryl transferase lipomodifies the cysteine residue in the signal peptidase II cleavage site. A site-directed mutation was introduced into gerD to change this potential site, Cys20, to Ala.

The phenotype of spore germination of AM1656 (gerD57; C20A) was only marginally less defective than that of the gerD-null (gerD97: : Tn917) mutant strain AM1622, with a very slow loss of OD in L-alanine, and essentially no loss in AGFK (Fig. 3). On Western blotting, no GerD protein was detected in AM1656 spores, either in integument or in the supernatant fraction (Fig. 2b, lanes 4 and 5), suggesting that the GerD protein is not retained efficiently in spores in this mutant. The reason for the loss of GerD protein from the developing spore has not been defined, but there are several possible consequences of the $\mathrm{C} 20 \mathrm{~A}$ substitution. If GerD is a lipoprotein, then a failure to lipomodify, as discussed in Tjalsma et al. (2004), may have resulted in a GerD protein in the inner forespore membrane that is subject to alternative processing, and that is released from the forespore before spore maturation within the mother cell, or alternatively it may have resulted in a retained membrane protein that is not processed appropriately, and is rapidly degraded.

\section{DISCUSSION}

The data presented here demonstrate that the GerD protein is present in the spore in the inner membrane, and that it is also present at very significant levels in the integument

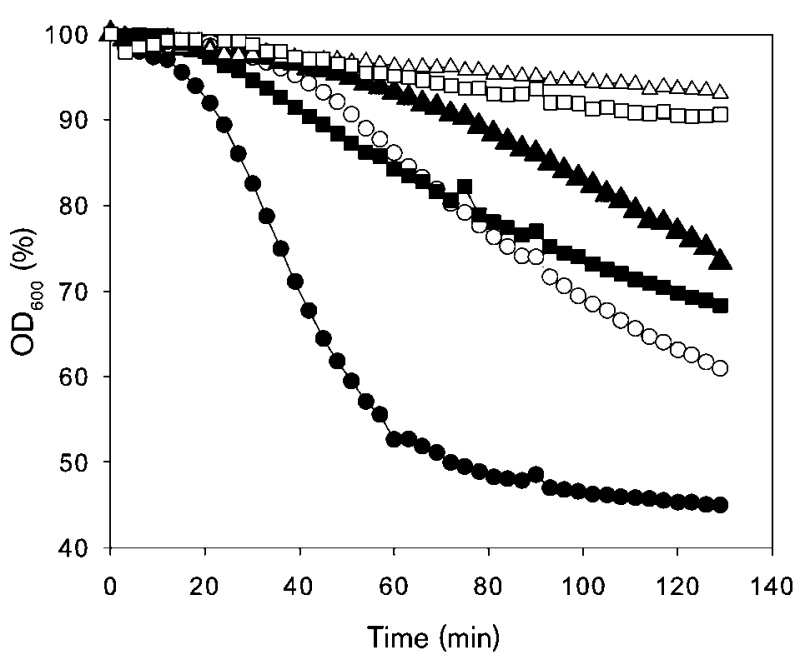

Fig. 3. Germination behaviour of ger $D$ mutant spores. Spores of 1604 (ger $^{+}$; circles), AM1622 (gerD::Tn917; triangles) and AM1656 (gerD57, C20A; squares) were prepared in CCY medium. The spores were then washed and heat activated, and germinated in L-alanine (filled symbols) and AGFK (open symbols).

fraction (probably in the germ cell wall), and to some extent in the soluble fraction. Very recently, authors of another publication used 20-fold overexpressed and FLAGtagged GerD, detected in coat-stripped spores, to demonstrate its presence in the inner membrane of spores (Pelczar \& Setlow, 2008). In this current work, probing for the authentic protein in wild-type spores demonstrated that the majority of the GerD protein could be dissociated to a monomer, and that much of it was present in integument material. The appearance in soluble fraction could reflect that some GerD protein is released from the inner membrane into soluble material outside the spore cellular compartment. The GerD protein in B. subtilis was present in multiple locations: inner membrane, integuments and soluble material. This may be fortuitous if it reflects simply the tendency of GerD protein to be released from the membrane; there are precedents for this, e.g. the lipoprotein of the oligopeptide transporter OppA is found in both membrane-bound and released forms (Perego et al., 1991), and there is evidence of release of a number of potential lipoproteins into the medium during vegetative growth of B. subtilis (Tjalsma et al., 2004). There is no understanding of the role of the GerD protein, but it is expressed in the forespore during sporulation, at approximately 20-fold higher levels than the GerA germinant receptor (Kemp et al., 1991). The gerD mutant phenotype could result from a defect in function, or in localization of germinant receptors. The most probable functional site of GerD would be in the inner membrane, where a number of proteins, such as germinant receptors, and SpoVA and SleB proteins, which are required for germination, are located; however, it is necessary to recognize that GerD 
protein located further out in the spore could have an additional or alternative role.

A recent report provides experimental evidence that GerD protein is a lipoprotein (Pelczar \& Setlow, 2008), as the overexpressed FLAG-GerD membrane protein detected in that work was larger, as if unprocessed, in an lgt mutant. Our complementary attempt to explore the localization of GerD protein when the potential for lipomodification was absent was not particularly informative, because the altered C20A protein was no longer present in the spore. This is consistent with the additional observation by Pelczar \& Setlow (2008) that a FLAG-tagged GerD protein when not overexpressed is not detected in spores of an lgt mutant; however, those authors were careful not to exclude the possibility that this was due to loss of the FLAG tag rather than the protein itself.

\section{ACKNOWLEDGEMENTS}

This research was funded by a scholarship to W. M. from the Royal Thai Government.

\section{REFERENCES}

Brown, W. C., Vellom, D., Ho, I., Mitchell, N. \& McVay, P. (1982). Interaction between a Bacillus cereus spore hexosaminidase and specific germinants. J Bacteriol 149, 969-976.

Chirakkal, H., O'Rourke, M., Atrih, A., Foster, S. J. \& Moir, A. (2002). Analysis of spore cortex lytic enzymes and related proteins in Bacillus subtilis endospore germination. Microbiology 148, 2383-2392.

Cowan, A. E., Koppel, D. E., Setlow, B. \& Setlow, P. (2003). A soluble protein is immobile in dormant spores of Bacillus subtilis but is mobile in germinated spores: implications for spore dormancy. Proc Natl Acad Sci U S A 100, 4209-4214.

Hudson, K. D., Corfe, B. M., Kemp, E. H., Feavers, I. M., Coote, P. J. \& Moir, A. (2001). Localization of GerAA and GerAC germination proteins in the Bacillus subtilis spore. J Bacteriol 183, 4317-4322.

Kemp, E. H., Sammons, R. L., Moir, A., Sun, D. \& Setlow, P. (1991). Analysis of transcriptional control of the gerD spore germination gene of Bacillus subtilis 168. J Bacteriol 173, 4646-4652.

Little, S. \& Driks, A. (2001). Functional analysis of the morphogenetic spore coat Bacillus subtilis protein CotE. Mol Microbiol 42, 1107-1120.

Moir, A. (2006). How do spores germinate? J Appl Microbiol 101, 526-530.

Moir, A., Lafferty, E. \& Smith, D. A. (1979). Genetic analysis of spore germination mutants of Bacillus subtilis 168 - correlation of phenotype with map location. J Gen Microbiol 111, 165-180.

Mongkolthanaruk, W. (2007). Functional analysis of spore germination proteins of Bacillus subtilis. PhD thesis, University of Sheffield.

Paidhungat, M. \& Setlow, P. (2000). Role of Ger proteins in nutrient and nonnutrient triggering of spore germination in Bacillus subtilis. $J$ Bacteriol 182, 2513-2519.

Paidhungat, M. \& Setlow, P. (2001). Localization of a germinant receptor protein (GerBA) to the inner membrane of Bacillus subtilis spores. J Bacteriol 183, 3982-3990.
Paidhungat, M., Ragkousi, K. \& Setlow, P. (2001). Genetic requirements for induction of germination of spores of Bacillus subtilis by $\mathrm{Ca}^{2+}$-dipicolinate. J Bacteriol 183, 4886-4893.

Pelczar, P. L. \& Setlow, P. (2008). Localization of the germination protein GerD to the inner membrane in Bacillus subtilis spores. $J$ Bacteriol 190, 5635-5641.

Pelczar, P. L., Igarashi, T., Setlow, B. \& Setlow, P. (2007). Role of GerD in germination of Bacillus subtilis spores. J Bacteriol 189, 10901098.

Perego, M., Higgins, C. F., Pearce, S. R., Gallagher, M. P. \& Hoch, J. A. (1991). The oligopeptide transport system of Bacillus subtilis plays a role in the initiation of sporulation. Mol Microbiol 5, 173-185.

Peterson, G. L. (1977). A simplification of the protein assay of Lowry which is more generally applicable. Anal Biochem 83, 346-356.

Robinson, C. (1996). A molecular analysis of the gerD and gerF spore germination genes of Bacillus subtilis 168. PhD thesis, University of Sheffield.

Scott, I. R. \& Ellar, D. J. (1978). Study of calcium dipicolinate release during bacterial spore germination by using a new, sensitive assay for dipicolinate. J Bacteriol 135, 133-137.

Setlow, P. (2003). Spore germination. Curr Opin Microbiol 6, 550556.

Setlow, B., Cowan, A. E. \& Setlow, P. (2003). Germination of spores of Bacillus subtilis with dodecylamine. J Appl Microbiol 95, 637-648.

Setlow, B., Wahome, P. G. \& Setlow, P. (2008). Release of small molecules during germination of spores of Bacillus species. J Bacteriol 190, 4759-4763.

Swerdlow, B. M., Setlow, B. \& Setlow, P. (1981). Levels of $\mathrm{H}^{+}$and other mono-valent cations in dormant and germinating spores of Bacillus megaterium. J Bacteriol 148, 20-29.

Tjalsma, H., Antelmann, H., Jongbloed, J. D. H., Braun, P. G., Darmon, E., Dorenbos, R., Dubois, J. Y. F., Westers, H., Zanen, G. \& other authors (2004). Proteomics of protein secretion by Bacillus subtilis: separating the "secrets" of the secretome. Microbiol Mol Biol Rev 68, 207-233.

Vepachedu, V. R. \& Setlow, P. (2007). Role of SpoVA proteins in release of dipicolinic acid during germination of Bacillus subtilis spores triggered by dodecylamine or lysozyme. J Bacteriol 189, 15651572 .

Warburg, R. J., Moir, A. \& Smith, D. A. (1985). Influence of alkali metal cations on the germination of spores of wild-type and GerD mutants of Bacillus subtilis. J Gen Microbiol 131, 221-230.

Yon, J. R. (1986). Analysis of a spore germination gene of Bacillus subtilis 168. PhD thesis, University of Birmingham.

Yon, J. R., Sammons, R. L. \& Smith, D. A. (1989). Cloning and sequencing of the gerD gene of Bacillus subtilis. J Gen Microbiol 135, 3431-3445.

Zheng, L. B., Donovan, W. P., Fitzjames, P. C. \& Losick, R. (1988). Gene encoding a morphogenic protein required in the assembly of the outer coat of the Bacillus subtilis endospore. Genes Dev 2, 10471054.

Zuberi, A. R., Moir, A. \& Feavers, I. M. (1987). The nucleotidesequence and gene organization of the gerA spore germination operon of Bacillus subtilis 168. Gene 51, 1-11.

Edited by: J. M. van Dijl 